\title{
Espaço do patrimônio em meio à profusão de notícias
}

institucional.us.es /ambitos/

Mary WeinsteinUniversidade Estadual do Sudoeste da Bahia

maryweinstein@gmail.com

\section{Resumen}

Na década de 1990, o governo da Bahia, Brasil, empreendeu a restauração do Centro Histórico de Salvador. O trabalho foi proposto na intenção de reabilitá-lo para impulsionar o turismo. Por conta disso, uma gentrificação foi promovida no conjunto colonial remanescente dos séculos 18 e 19, considerado Patrimônio da

Humanidade. A imprensa, estimulada pela novidade da iniciativa de interromper 0 processo de arruinamento, passou a cobrir o evento. Neste artigo, o objetivo é

mostrar como o jornal A Tarde acolheu a temática. Como base teórica, utilizamos noções de agendamento (McCombs, 2007), publicização (Habermas, 1984) e

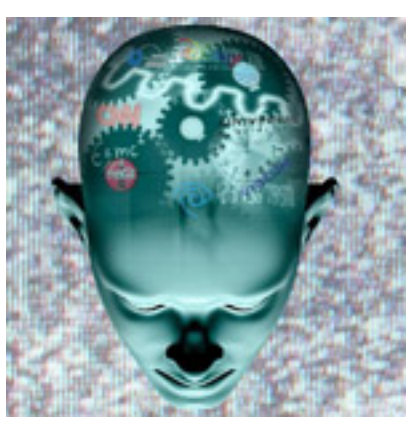
narrativa do fato (Sodré, 2009).

\section{Palabras clave}

Gentrificação, Centro Histórico, imprensa, agendamento.

\begin{abstract}
In the 1990s, the government of Bahia, Brazil, undertook the restoration of the Historic Center of Salvador. The work was proposed to rehabilitate it in order to boost tourism. Therefore, a gentrification occurred on this site of the $18^{\text {th }}$ and $19^{\text {th }}$ centuries considered World Heritage. The press, stimulated by the novelty of the initiative to stop the process of blasting houses, covered the event. In this article, the aim is to show how the traditional newspaper A Tarde accepted the theme. As a theoretical basis, we use notions of agenda-setting (McCombs, 2007), publicizing (Habermas, 1984) and fact narrative (Sodré, 2009).
\end{abstract}

\section{Keywords}

Gentrification, Historic Center, press, scheduling.

\section{INTRODUÇÃO}

Nos anos 1990, o Centro Histórico de Salvador, conjunto colonial formado por casarões remanescentes dos séculos 18 e 19, mudou em pelo menos dois aspectos: parte do seu casario foi restaurada, o que contribuiu para retardar o processo de degradação em que se encontrava; e a população moradora foi relocada para dar lugar a uma preservação que tinha como principal objetivo promover tanto o turismo quanto o proponente da ação, o governo do Estado da Bahia.

A imprensa local acompanhou o processo dessas duas transformações e é a partir desta condição que o nosso objeto de análise é apresentado. Demonstraremos que a imprensa agendou a iniciativa de restaurar o Centro Histórico, e, por tabela, o governo do Estado, correspondendo à expectativa de que a ação obtivesse repercussão midiática. Buscamos evidenciar que, ao contribuir para a divulgação da empreitada, abriu-se uma lacuna no diálogo público, uma vez que, inicialmente, prevaleceu o agendamento com base predominantemente nos interesses de divulgação do governo e sem a correspondência equitativa da representação dos moradores da área alvo da recuperação.

A cobertura jornalística acerca da restauração do Centro Histórico de Salvador que a mídia empreendeu a partir de 1992, quando o governo iniciou o Programa de Recuperação, se destaca no horizonte jornalístico como o período de uma trajetória em que um assunto é agendado e permanece em discussão na esfera pública, embora passando por reelaborações sucessivas no que se refere aos seus atributos mais evidenciados e ao seu enquadramento. 
Debruçamonos especificamente sobre a atuação do jornal A Tarde, que completou 101 anos, e sua abordagem sobre o Centro Histórico no momento de sua recuperação, buscando contextualizar e observar, no elenco de matérias publicadas, a forma como a temática do patrimônio foi acolhida e em que medida o jornal reproduziu o discurso oficial em detrimento da representação dos moradores locais, contribuindo para a abrupta gentrificação que se efetivou no local.

\section{BREVE HISTÓRICO}

O Centro Histórico, com suas edificações dos séculos 19 e 20, foi tombado em 14 de julho de 1959. A reratificação e ampliação da área foram decretadas em 1983, e a classificação deste espaço como Patrimônio da Humanidade se deu em 1985. Apesar de todas essas patentes oficiais e do sentido que tinha e produzia para populações locais, a área sofreu intenso processo de degradação ao longo da maior parte do século 20 . Desde as décadas de 40 e 50, notícias saíam nos jornais dando conta das condições dos seus casarões e de vida das pessoas que ali habitavam. Tentativas de recuperação eram pleiteadas, publicamente, nos jornais, por personalidades diversas, e reformas eram esporadicamente anunciadas, começadas, paralisadas e abandonadas. Até que, na década de 90 , iniciou-se uma operação que se transformou em assunto constante na mídia regional e nacional, em decorrência da expectativa construída, em grande parte pelos próprios meios de comunicação, em torno do sucesso que se vislumbrava. Esta recuperação iniciada na década de 90 mantém-se agendada até hoje.

A história da recuperação do Centro Histórico proposta pelo Governo do Estado da Bahia começou em 1992, com a I Etapa de um Programa de Recuperação. A iniciativa foi primeiramente divulgada em uma entrevista do tipo ping-pong, em A Tarde, o maior jornal do Estado, o de maior credibilidade e popularidade, no mesmo ano. Há uma década, este mesmo programa de recuperação encontra-se em sua $7^{\mathrm{a}}$ Etapa. Governos se sucederam, assim como os direcionamentos de suas diversas políticas públicas. Entretanto, a condição do Centro Histórico permaneceu necessitando de especial atenção para que o risco iminente de deterioração do conjunto não se concretizasse.

Este histórico que se segue, contendo informações sobre o sítio recuperado e sua população, assim como a trajetória do jornal A Tarde, permite que sejam entendidas as relações que se desenvolviam e que passaram a se desenvolver durante o Programa de Recuperação promovido pelo governo do Estado da Bahia e a cobertura jornalística oferecida. Este histórico contribui para a compreensão da questão sociocultural do Centro Histórico.

\subsection{Centro Histórico}

O Centro de Salvador se mantém como testemunho da história. No início, o seu miolo, o Pelourinho, era predominantemente residencial, próximo à área administrativa da Praça Municipal e comercial da Cidade Baixa, conforme organização ditada pelo projeto do arquiteto-mor, Miguel de Arruda, trazido de Portugal pelo mestre Luis Dias, que chegou com o primeiro governador-geral do Brasil, Tomé de Souza. A cidade começou a se modificar e a se reconfigurar espacialmente conforme crescia em população a ponto de provocar as primeiras preocupações de Wanderley de Pinho com o patrimônio histórico e cultural. No começo do século 20, Pinho, um dos precursores da conservação do patrimônio na capital baiana, apontou atitudes equivocadas, ao mencionar diversos impedimentos encontrados para a proteção do patrimônio. Desde a adulteração de fontes e prédios "fontes públicas que se rebocam e reformam, tapando inscripções e quebrando cornijas; velhos solares que se mutilam; capelas e templos que se deixam ruir (...)" (PINHO, 1990) -, até a falta de recursos - "onde encontraremos fundos para custear despesas em conservar o que se vae arruinando ou transportar e abrigar o que se vae perdendo?" (PINHO, 1990). Durante as duas décadas seguintes ao discurso de Pinho, o "progresso demolidor" se alastra destruindo monumentos pelo Brasil afora, e especialmente em Salvador, onde os jornais acompanham os fatos e abrem espaços para a discussão pública:

Essa ideologia do progresso, reduzida aos aspectos urbanísticos da Cidade do Salvador, vai encontrar seus sectários acastelados na imprensa diária. Os jornais baianos irão indiscutivelmente colaborar na criação de uma opinião pública, não diremos favorável ao urbanismo demolidor, mas pelo menos, deslumbrada e anestesiada em relação ao mesmo. A doutrinação encherá páginas e páginas de vários jornais, nas primeiras décadas do século XX, todos acentuadamente defensores das reformas. Em 1912, não surgirão protestos e vozes 
discordantes, como em 1928 e 1933, e o tônus será, mesmo de certos membros da inteligência baiana, como veremos adiante, de vôo cego e impensado amor ao "progresso", com o sacrifício iconoclasta de nossos monumentos históricos (PERES: 2009: 38).

Em 1959, ano do tombamento nacional, assim era descrito o Pelourinho por Milton Santos, que faz um relatório sobre as condições de degradação social e arquitetônica da área. Ele relaciona os que vivem sem ocupação definida e descreve o estado de miséria daqueles que moram nos quartos subdivididos por "panos", que abrigavam três a quatro pessoas, as mesmas que seriam afastadas durante o processo de recuperação de que tratamos. Santos via a imposição jurídica que controlava as condições na ordenação da cidade.:

O Pelourinho é uma ladeira-praça, de forma irregular, rodeada por edifícios dos séculos 18 e 19, grandes casas nobres de dois e de três andares que serviram como residências a famílias ricas, mas que hoje caíram em ruínas. O interesse do estudo dessa praça reside no fato de que ela se situa no coração mesmo da área resguardada pelos regulamentos que asseguram proteção aos monumentos históricos da cidade. Assim, ela representa, a um só tempo, um exemplo da influência dos valores jurídicos sobre os fatos de estrutura urbana e um exemplo de degradação (SANTOS, 1959:165-66).

O pensamento de Santos sobre o Pelourinho, também, é publicado nos jornais. Na Tribuna da Bahia, na mesma época. "Há uma geografia de Prostituição?" (29/4/1959), com o seguinte apoio explicativo: "A 'limpeza' da cidade velha - quando o problema não é só policial - atividade urbana tem razão econômica - soluções exóticas não servem para sanear a zona proibida".

Pouco depois da análise de Santos (1959), sobre o Pelourinho, Torres (1961) faz uma listagem dos logradouros da Sé, tentando vislumbrar o destino de cada um deles e, de algum modo, inventariando ruas ao citar seus nomes, alguns que já iam sendo substituídos. Interessante observar que tanto Santos, quanto Torres - este ampliando a área referencial - referem-se ao espaço em questão como "coração da área resguardada" e "coração da capital", dando-Ihe a ideia de centralidade e de proximidade afetiva (TORRES, 1961:25-26).

A ocupação dos demais bairros do Centro Antigo, também, começou a se transformar quando, por volta dos anos 70 , localidades mais afastadas passaram a atrair antigos residentes de Nazaré, Desterro, Campo da Pólvora, dentre outras. Na década de 80 , aumentou o número de adeptos das novas áreas residenciais. Trocavam-se as ruas do Centro pelas da Pituba, que se expandia, e, pouco depois, já propiciava a formação de sub-bairros, como o do Itaigara, Parque da Cidade e Caminho das Árvores. Os edifícios agora mais altos eram construídos com playground, piscinas e quadras de esportes. Enquanto isso, o Pelourinho e circunvizinhança se degradavam ainda mais porque deixaram de exercer atração sobre as classes que poderiam sustentá-lo com impostos e dignidade.

O processo de degradação da área do Pelourinho, área nobre da cidade, é o resultado da crise econômica do século passado e do livre jogo das forças econômicas na dinâmica de transformação que condicionou o tipo específico de crescimento da cidade, causando a desvalorização das zonas de construções antigas. Essa desvalorização econômica conduziu fatalmente à desvalorização social, forçando a mobilidade centrífuga dos moradores de maiores posses, e aumentando a força de atração sobre os grupos situados nos quadros mais baixos da hierarquia do sistema de estratificação social (ESPINHEIRA, 1984:69).

A região do Pelourinho passou a ser ainda mais desdenhada pelas classes alta, média e baixa, ao perder as utilidades que tinha, quando deixou de ser área residencial e comercial. Como consequência da falta de interesse econômico voltado para aquele espaço, os seus atrativos arquitetônicos se deterioravam ao deixarem de ser conservados pelos poderes públicos e pelos próprios donos dos imóveis. Salvador optava por um novo e diferente modo de vida, que excluía o Centro Histórico, e, sobretudo, o estigmatizava.

As prostitutas convergiram para o Pelourinho, por um lado, atraídas pelas condições sociais e econômicas da localidade, enquanto que, por outro, aí se estabeleceram compelidas pela ação policial dos órgãos encarregados dos costumes (ESPINHEIRA, 1984:70).

Por vezes, o sociólogo Gey Espinheira se refere aos jornais como documentos que evidenciavam "o caráter patológico dessa comunidade e da ação policial que aí se faz constante" (ESPINHEIRA, 1971:43). O sociólogo 
baiano considerava a "análise dos comportamentos divergentes documentados por notas jornalísticas" um complemento para o seu "estudo exploratório". Ele se refere ao conteúdo dos jornais como a "opinião popular, traduzida pela imprensa", que permite verificar o grau de discriminação social (ESPINHEIRA, 1971:43).

A re-ratificação do tombamento do Centro Histórico ocorreu em 20 de outubro de 1983, com inscrição no Livro do Tombo, em 19 de julho de 1984. A Folha de São Paulo saiu com matéria um dia depois:

Foi tombado ontem pelo Conselho Consultivo da Secretaria do Patrimônio Histórico de Salvador, o Centro Histórico de Salvador, uma área aproximadamente de 750 mil metros quadrados, com cerca de 60 mil imóveis e 28 monumentos que, no próximo ano, vai ser indicada à Unesco para se tornar patrimônio mundial da humanidade (Folha de São Paulo, 21/10/1983).

A Tarde publica, com chamada apenas ao pé da primeira página, Salvador reconhecida "Cidade Monumento", com fontes oficiais: o prefeito Manoel Castro e o superintendente do Serviço do Patrimônio Histórico e Artístico Nacional (Sphan), Ary Guimarães. Houve chamada na capa do jornal, e não manchete. Outras seis matérias sobre patrimônio, relacionadas e não relacionadas à classificação de Patrimônio da Humanidade, seriam publicadas ainda neste mesmo mês. Apenas uma delas, sobre a restauração da Igreja da Piedade terá chamada de capa. Ou seja, o Centro Histórico de Salvador é classificado como Patrimônio da Humanidade e na capa do maior jornal do estado este acontecimento rende apenas uma chamada situada ao pé da primeira página, com foto de $176 \mathrm{cms}^{2}$, e não manchete, mesmo diante dos valores-notícias ineditismo, novidade, número de pessoas afetadas, proximidade etc.

Fernandes (2008:30) discorre sobre a série de circunstâncias que forjaram o esvaziamento do Centro, no século 20. Ela menciona um novo modelo de expansão urbana, decorrente da mudança de padrão de crescimento de Salvador para uma lógica industrial-metropolitana. Além do aumento demográfico, nos anos 50 a Petrobras se instala e começa a exploração de petróleo no Recôncavo baiano. O Centro Industrial de Aratu nos anos 60, a implantação do Pólo Petroquímico de Camaçari na década de 70 e, no início dos anos 2000, os investimentos vinculados à indústria automobilística, também em Camaçari, desloca a concentração de trabalhadores das proximidades do Centro. "Essa nova lógica construída ao longo de 40 anos, será marcada por diversas ações intra-urbanas que aceleram ainda mais o processo de perda de ritmo de crescimento da área central da cidade" (FERNANDES, 2008:30).

Como pudemos observar até aqui, as matérias veiculadas pelos jornais apontam os aspectos negativos do Centro Histórico e a motivação para o ambiente degradado apontava sempre na direção da população que lá morava. Desde a década de 60, estudos vinham sendo feitos para preservação de conjuntos tombados com o objetivo de incrementar o turismo que mais tarde viria a se confirmar como política.

\subsection{A Tarde}

Fundado por Ernesto Simões Filho e em circulação no Estado da Bahia e em Sergipe, o A Tarde perdeu a posição de mais vendido justamente quando alcançava o seu centenário. Entretanto, ainda hoje, mantém-se como periódico de credibilidade no Estado. Ao longo de sua história, o jornal foi o de maior tiragem e vendagem. Essas posições foram perdidas muito como consequência de uma reestruturação do seu concorrente, o Correio da Bahia, pertencente à família do finado e controvertido governador Antônio Carlos Magalhães, o qual foi o proponente da recuperação do Centro Histórico, sítio que serve de motivação para esta análise sobre o objeto jornalístico.

O Correio, como passou a ser chamado exatamente para se afastar do espectro do seu antigo proprietário, adotou o formato berliner, diminuiu drasticamente o seu preço ao consumidor e reformulou a padronização de suas matérias, que passaram a ser curtas e sintéticas, ocupando menor espaço nas páginas na publicação. Também, uma intensa campanha de marketing passou a ser veiculada no canal de TV pertencente ao mesmo grupo que edita o Correio.

No período em que foram publicadas as unidades jornalísticas que compõem o corpus empírico deste trabalho, o jornal A Tarde era o impresso com maior popularidade e vendagem no mercado jornalístico local. Por meio de uma análise de conteúdo, cujo recorte empírico são as unidades jornalísticas publicadas em A Tarde entre 1992 
e 2002, descrevemos a trajetória do jornal em sua abordagem sobre a recuperação do Centro Histórico.

\section{ESPAÇO PÚBLICO E QUESTÕES TEÓRICAS}

A esfera pública é o espaço de mediação onde se pronuncia o diálogo, pretensamente travado entre sociedade e governo, envolvendo diversos interesses desde a Modernidade. A mídia é a intermediação. Esta é uma contingência que afeta a todos os que convivem em comunidade. A imprensa, como espaço privado que se presta à discussão pública, dirige-se aos públicos que consomem o que é produzido pelos meios de comunicação e, certamente, aos que não. Porque a esfera pública implica em contaminação natural entre os que a compõem. A recepção se expande, se amplia, ou se reduz, como pressupõem as teorias, particularmente, a da Agenda-Setting (McCOMBS, 2007), a qual utiliza a ideia de transferência entre agendas da mídia, do público e a dos governos. Para que a recepção se expanda, o assunto precisa ser agendado, ter uma determinada saliência, conforme os preceitos definidos por McCombs (2007).

A transferência que ocorre em consequência da interação entre agendas é a própria razão de ser da teoria. Partimos do pressuposto de que a agenda da mídia influencia a agenda do público. Então, neste trabalho, observamos a agenda midiática a partir da constatação do seu agendamento. Não nos atemos às diferenciações entre Agenda-setting e Framing, com referência aos seus atributos mais evidenciados e não ao seu enquadramento (WEAVER: 2007). Para chegarmos a um segundo nível da Agenda-setting, nos utilizamos da identificação desses atributos. A nossa análise se detém na constatação do agendamento, sem delimitar a influência deste no público.

Habermas descreveu a mudança estrutural na esfera pública considerando o jornalismo em sua capacidade de publicizar as mensagens, e também, analisou o seu papel. Há uma síntese da relação que se estabelece quando se tem a imprensa como veículo útil aos propósitos nem sempre anunciados, mas, quase sempre, implícitos na interação da ação política:

A "cultura" difundida através dos meios de comunicação de massa é particularmente uma cultura de integração: ela integra não só informação e raciocínio, as formas publicitárias como as formas literárias e beletrística psicológica para uma ocupação e "ajuda de vida" determinada pelo human interest; ela é suficientemente elástica para também assimilar, ao mesmo tempo, elementos da propaganda, até mesmo para servir como uma espécie de super-slogan que, caso ainda não existisse, poderia ter sido simplesmente inventado para fins de public relations do status quo /84\%. A esfera pública assume funções de propaganda. Quanto mais ela pode ser utilizada como meio de influir política e economicamente, tanto mais apolítica ela se torna no todo e tanto mais aparenta estar privatizada /85/ (HABERMAS, 1984:207-208).

E a notícia acaba se tornando uma aliada de empreitadas, legitimando a existência de produtos, quando os coloca em evidência e propõe uma reflexão conforme propósitos definidos pelo próprio proponente do assunto.

A notícia é mesmo uma forma incipiente da 'economia da atenção' que terminou caracterizando a mídia contemporânea. É, assim, um produto - e certamente caro, considerando-se o custo atual da sua produção na esfera da grande mídia - cuja identidade mercadológica se configura a partir de meados do século XIX, no momento de transição do publicismo ou 'jornalismo de opinião' (caracterizado pela produção artesanal, pela periodicidade irregular e por textos fortemente polêmicos) para a 'imprensa comercial', organizada em bases industriais, logo voltada para um público massivo, suscetível de sustentar grandes tiragens e assegurar o lucro (SODRÉ: 2009, 25).

Portanto, é possível pressupor que a mídia pode se tornar uma aliada do agendamento proposto por determinados proponentes ou pelo agendamento promovido pelo governo ou pelo agendamento do público, sendo esta, a mídia, direcionadora da "economia da atenção" mencionada pelo autor. Seria o que os psicólogos sociais chamam "objeto da atitude" - algo para o qual a atenção do público é dirigida. Este entendimento coincide com a ideia de saliência desenvolvida por McCombs (2007).

\section{A COBERTURA DO JORNAL}

Dentro do espectro empírico definido neste trabalho - que são as unidades jornalísticas publicadas entre o 
lançamento do Programa de Recuperação e o seu quarto ano de aplicação - em nenhuma matéria em A Tarde, neste período, foi incluída a questão da concorrência de poderes ou responsabilidades sobre o Centro Histórico. Em função do tombamento nacional do referido sítio, há uma poligonal em que prevalece a jurisdição federal. Entretanto, todo o Programa de Recuperação foi idealizado e executado por uma instância governamental diversa, a do Estado da Bahia.

A rapidez com que a "recuperação" foi feita, o seu resultado e a desterritorialização dos seus antigos moradores têm sido motivo de estudos acadêmicos e ainda rendem desdobramentos na própria mídia quando confrontados com o estado em que se encontra o mesmo espaço, hoje. A não disputa em torno das responsabilidades e cuidados acerca do Patrimônio Cultural, entre o Instituto do Patrimônio Histórico e Artístico Nacional (Iphan), responsável a nível federal, e o governo local tornou-se um exemplo de um conflito dissimulado, sem discussão explícita na esfera pública. Jornalisticamente, o episódio propiciou a participação da mídia como mediadora de discussões que envolviam interesses distintos - o do governo do Estado que queria utilizar a área para catapultar o marketing da sua gestão e o dos antigos moradores que não pretendiam ser evacuados por conta da revalorização da área. O governo tratava a questão como uma "obra" capaz de render votos e notoriedade, a partir do reconhecimento da sociedade, que queria ver o patrimônio do conjunto colonial reabilitado ou apreciava a ideia de usar o Pelourinho como local de entretenimento. Os moradores, por sua vez, encontravam dificuldades para manter o direito de permanecer na área.

A imprensa, ainda que tardia e pontualmente, não se eximiu de mostrar a situação da população na condição de praticamente obrigada a se transferir do Centro Histórico para outras partes da cidade, no que ficou conhecido como “assepsia social", umtermo usado em um processo iniciado pelo Ministério Público Estadual. No seguinte trecho do trabalho Desapropriação das memórias indesejáveis: opressão e resistência no Centro Histórico de Salvador, de Juliana Neves Barros e Vanessa Souza Pugliese, "aqui, muito mais que antes, fica escancarado o intento de 'assepsia social do estado': os moradores atuais, portadores da identidade cultural do lugar, deveriam deixar seus imóveis e serem substituídos por outro perfil populacional”, para que a "recuperação" do sítio pudesse ser feita.

O jornal A Tarde manteve cobertura ao longo de todo o processo, com abordagem de vários atributos (McCombs, 2007). De um ano para outro, a quantidade de matérias sobre o patrimônio duplicou. Seguindo esta construção de agendamento, o número de matérias sobre o patrimônio cultural material da cidade, ao mesmo tempo, também, foi aumentando e sendo ampliado.

Conforme entendimento do funcionário de A Tarde Paixão Barbosa, em entrevista feita por esta pesquisadora em 13/12/2008 e em 10/06/2010, o jornal cobriu de forma imparcial os eventos relacionados ao Centro Histórico, durante o início da sua recuperação. Segundo o jornalista, repórteres e editores tinham autonomia para tratar o assunto.

A Redação não recebia orientação para ficar contra ou a favor do governo nem da oposição. Na década de 90 , o grupo político mais forte no Estado, liderado pelo governador (1991-1995) e senador (1995-2007) Antonio Carlos Magalhães, procurava influenciar o noticiário a partir de ligações pessoais com alguns dos dirigentes da Redação, mas isto não conseguiu lhe dar o controle do noticiário. Tanto é que, em 1998, o governador César Borges, seguindo a orientação do grupo, rompeu relações com o jornal, cortando, inclusive, toda a publicidade oficial (WEINSTEIN: 2011, 247).

\section{ANÁLISE DA TRAJETÓRIA DA COBERTURA}

O Programa de Recuperação do Centro Histórico de Salvador e o tombamento do Corredor da Vitória envolveram disputas e diálogos entre campos sociais. Quantificações subsidiam a análise sobre a cobertura de A Tarde durante esses episódios. Revemos as unidades jornalísticas publicadas e descrevemos a formulação da produção neste jornal. A análise de conteúdo aplicada à cobertura se constitui na verificação da intermediação do conflito pelo referido veículo.

Instituímos como base de análise da pesquisa empírica unidades jornalísticas - notas, reportagens, artigos, editoriais etc - publicadas no jornal A Tarde, e consideramos, também, os contextos concernentes a cada produção. Não ignoramos particularidades dos enunciados como articulações e associações, que cabem ao 
repórter fazer. Essas informações, também, são consideradas, junto com as quantificações. A "atitude interpretativa" não é desconsiderada na análise de conteúdo (BARDIN, 2008: 16). Conforme Sousa (2006: 354), a análise qualitativa de um discurso pode ser aplicada às "qualidades não quantificáveis". Porque, como complementa Wolf (2005:168), medir a importância de um argumento com base somente no número de vezes em que o tema é mencionado não é suficiente frente à complexidade dos fenômenos cognitivos envolvidos.

A verificação da abordagem do episódio substancia a hipótese de que houve um processo de construção de uma pauta sobre o assunto a partir do acontecimento da recuperação e a de que o jornal não reservou espaço de forma equilibrada para a representação dos moradores que foram levados a sair do Centro Histórico, buscando outros locais para moradia. Houve modificações na forma de abordagem de A Tarde, quanto a aspectos referentes à continuidade de agendamento, tematização, inserção de representação das vozes e hierarquização de assuntos relacionados ao patrimônio. Percebemos que a inserção da notícia sobre patrimônio surge a partir de acontecimentos que afetaram interesses de grupos diversos. Ao descrevermos a trajetória dessa cobertura, com índices resultantes de levantamentos feitos com este objetivo específico, capacitamo-nos a inferir sobre: 1) apresentação de conflitos e representação de vozes, com base na quantificação da inserção de temas e fontes no corpo dos textos publicados; 2) engajamento do jornal e identificação de transferência de agendamento.

A análise está baseada nos dados contidos no texto jornalístico e na distribuição das matérias no jornal. Para esta pesquisa, concentramos como "população" as edições entre 1992 e 1996. Na análise de conteúdo é definida uma população que, como compreendemos, corresponde ao universo do qual será selecionado o corpus da análise. De imediato, selecionamos as matérias sobre patrimônio cultural material e, dentro deste grupo, separamos as que tinham relação com a recuperação do Centro Histórico de Salvador.

\subsection{Atributos da mesma temática}

As matérias sobre patrimônio cultural incluem igrejas, museus, acidentes e iniciativas do governo, relativas ao Estado da Bahia. Dentro deste universo, nos concentramos em objetos e questões situados em Salvador e relacionados direta ou indiretamente ao Centro Histórico nas áreas definidas para recuperação pelo programa anunciado em 1992 e/ou processos que tinham como foco o Pelourinho, o Centro Histórico e o entorno imediato. 
Tabela I - Atributos de matérias publicadas

\begin{tabular}{|c|c|c|c|c|c|}
\hline Assuntos & 92 & 93 & 94 & 95 & Total \\
\hline Baixa dos Sapateiros & 0 & 2 & 1 & 0 & 3 \\
\hline Banheiro & 0 & 0 & 1 & 0 & 1 \\
\hline Comércio & 0 & 0 & 1 & 5 & 6 \\
\hline Degradação & 2 & 2 & 5 & 3 & 12 \\
\hline Desabamento & 1 & 4 & 6 & 4 & 15 \\
\hline Entorno & 0 & 3 & 2 & 2 & 7 \\
\hline Etapa atrasada & 0 & 0 & 3 & 1 & 4 \\
\hline Habitação & 0 & 0 & 0 & 0 & 0 \\
\hline Imprensa & 0 & 2 & 2 & 1 & 5 \\
\hline Inauguração de etapas & 12 & 38 & 9 & 0 & 59 \\
\hline Incêndio & 8 & 2 & 2 & 0 & 12 \\
\hline Instalação de empreendimentos & 4 & 22 & 11 & 6 & 43 \\
\hline Iphan & 0 & 0 & 0 & 1 & 1 \\
\hline Moradores & 2 & 3 & 3 & 4 & 12 \\
\hline Queixa, denúncia & 3 & 1 & 3 & 2 & 9 \\
\hline Prefeitura/Praça da Sé & 3 & 2 & 2 & 1 & 8 \\
\hline Recuperação & 4 & 21 & 10 & 6 & 41 \\
\hline Restauração & 9 & 0 & 4 & 0 & 13 \\
\hline Retirada de morador & 8 & 2 & 0 & 0 & 10 \\
\hline Segurança & 1 & 8 & 4 & 4 & 17 \\
\hline Trânsito & 1 & 7 & 1 & 5 & 14 \\
\hline Turismo & 0 & 8 & 2 & 5 & 15 \\
\hline Verbas & 4 & 0 & 4 & 1 & 9 \\
\hline Visitas ilustres & 0 & 10 & 7 & 8 & 25 \\
\hline Total & 59 & 137 & 84 & 60 & 342 \\
\hline
\end{tabular}

Fonte: Pesquisa efetuada pela pesquisadora com base em matérias publicadas

em A Tarde entre 1992 e 1995.

Os indicadores a serem quantificados são referentes à frequência das inserções, às fontes incluídas nas matérias. A recuperação foi levada à imprensa, especialmente os assuntos considerados positivos pelos seus promotores. As notícias consideradas "positivas" são as que, em geral, se referem às inaugurações de obras e etapas e instalação de empreendimentos.

\subsection{Análise anual}

Em 1992, a recuperação do Centro Histórico de Salvador apareceu vigorosamente na mídia dando mostras que, dessa vez, ao contrário das anteriores em que outras foram anunciadas, seria executada. Os acontecimentos referentes a essa empreitada continham valores-notícia - novidade, relevância, abrangência, proximidade, atualidade, expectativa -, capazes de despertar e manter em alta o interesse público, que justificaria o agendamento do assunto. A recuperação passava a ser tratada por vários veículos. De acordo com os registros obtidos com a contagem de matérias, as inserções sobre o Centro Histórico - especificamente sobre o processo que se iniciava e sobre outros acontecimentos, também -, passaram a ser incluídas regularmente no jornal.

Até 1992, quando a recuperação do Centro Histórico foi anunciada, as reportagens costumavam ser esporádicas, predominantemente sobre incêndios e desabamentos. A abordagem desses temas não foi 
suprimida com o anúncio da primeira etapa, mesmo porque os acidentes não deixaram de acontecer. Este atributo foi "gancho" para oito matérias, sendo que uma delas - Fogo destrói mais um casarão secular no Centro Histórico (A TARDE, 2/1/1992: 11) -, foi uma das sete que obteve chamada na primeira página que o assunto patrimônio emplacou.

Até 15 de março de 1992, quando foi publicado o ping-pong "Antônio Carlos: Bahia influi nas decisões nacionais" (A TARDE, 15/03/1992:10), já tinham sido veiculadas, em A Tarde, sete matérias sobre incêndio ou com conteúdos correlatos, relativas a bombeiros e a colocação de hidrantes. Ou seja, dentro do espectro do patrimônio, o fogo seguia como um dos assuntos mais cotados até que a recuperação fosse anunciada. A temática arrefeceu nos anos seguintes, caindo para apenas duas matérias por ano, voltando a aumentar em 1997 e 1998, quando a recuperação do Centro Histórico teve o seu ritmo desacelerado.

$\mathrm{Na}$ entrevista veiculada em 15 de março de 1992 e classificada para quantificação nesta pesquisa na categoria "Inauguração, anúncio de etapas", ACM menciona que pretende restaurar pelo menos três quarteirões do Centro Histórico. Sua intenção, como ele diz, é a de "mostrar que o lugar é turisticamente viável". Apenas cinco dias depois, o jornal saiu com um editorial pedindo a "preservação do passado", tendo como gancho a restauração do Instituto Histórico e Geográfico da Bahia, situado na Praça da Piedade, Centro Antigo, "bastião de lutas em favor da conservação do patrimônio". A recuperação passa a ser considerada e destacada como tema de relevância. O assunto ganha continuidade, torna-se recorrente e com diversificação de atributos. Por enquanto não havia nada a respeito dos moradores do local.

A partir de 22 de abril de 1992, quando ACM garante que a recuperação começaria no prazo de 60 dias (A TARDE, 22/04/1992:2) com obras em 100 casarões, começam a ser mais frequentes as inserções sobre patrimônio. Desde instalações de novos empreendimentos no Pelourinho, até as providências que eram tomadas para a recuperação, passaram a ser motivos para que o patrimônio saísse no jornal. Detalhes se tornaram relevantes para garantir a publicação de uma variedade de aspectos concernentes à recuperação que se mantinha em evidência. As matérias enfocavam mais especificamente o empreendimento da recuperação, e acompanhavam a expectativa de se ter o patrimônio restaurado. Publicizava-se não só o patrimônio, mas, também, os promotores da ação, mas não na mesma proporção os moradores que carregavam a cultura local. Anúncios de início e de licitação de obras, pedidos de explicações de empresas que se habilitam a executá-las passaram a ser pretextos para uma variedade de matérias. Este foi o ano com o segundo maior número de inaugurações reportadas.

Em 1993, a euforia das inaugurações motiva muito mais o agendamento do que a realidade dos moradores e a metodologia da intervenção arquitetônica. Embora não especificado na Tabela 2, o assunto, também, frequentou a coluna social mais conhecida de A Tarde, a de July. A recuperação apareceu neste local do Caderno 2 por, pelo menos, 16 vezes, em 1993. O assunto também foi motivo de informes publicitários. No dia 30 de março, quando os jornais destacaram a inauguração da I Etapa de Recuperação do Centro Histórico, a empreiteira Soares Leone, uma das que foram contratadas para executar as obras do Programa, publicou anúncio de meia página, na página 5 . O ano de 1993 foi o que reuniu o maior número total de matérias, que em sua maioria foi de apoio à iniciativa do governo estadual. Houve uma matéria sobre a "retirada de moradores". Essas cinco referências não conferiam uma significativa saliência se confrontadas ao número de reportagens com conotação positiva ao empreendimento como um todo. Foram 37 sobre inaugurações, anúncios e etapas de obras e outras 21 sobre recuperação em geral.

A cada visita de políticos, a cada novo anúncio, a cada nova obra eram publicadas notas, reportagens, artigos e editoriais, a maioria contendo elogios e demonstrações de apoio irrestrito e adesão à empreitada. As menções ao Centro Histórico estão repletas de informações sobre as realizações e propostas do governo. Se a grande motivação para matérias são as iniciativas do governo de recuperar, houve uma especificação maior de atributos, ou seja, mais assuntos se transformaram em pautas conferindo uma maior diversidade de temáticas, todos elas relacionadas ao processo que se iniciava no Centro Histórico de Salvador e que se prolongou até a década seguinte. Praticamente, não houve matérias críticas ao Programa.

Em números absolutos, 1994, teve 23 matérias a menos sobre patrimônio histórico e cultural em relação ao ano anterior. Delas, 100 unidades tratavam do Centro Histórico. O número de matérias relacionadas ao Centro 
Histórico e a sua recuperação diminuiu, proporcionalmente. Com a continuação do Programa de Recuperação, já em seu terceiro ano de execução, e segundo ano de inaugurações, as atenções da mídia permaneciam voltadas para o Centro Histórico e para as ações em favor da sua restauração.

O ponto novo em termos de conteúdo é o surgimento de matérias sobre o entorno da área que estava sendo restaurada e assuntos correlatos, como segurança, este já presente no ano anterior com quatro inserções. $A$ direção do Instituto do Patrimônio Artístico e Cultural (Ipac) havia mudado. O antropólogo Vivaldo da Costa Lima deixara o cargo e a arquiteta Adriana Castro assumiu. As inserções midiáticas aumentaram.

Somente neste terceiro ano, surgem notícias críticas direcionadas à qualidade da "restauração". "Casarões recuperados já apresentam infiltrações" (A TARDE, 26/04/1994), se refere à descoberta de defeitos nas obras dos casarões. Não houve desdobramentos para esta matéria, cujas fontes foram um representante da empreiteira Soares Leone e outro do Ipac.

A Tarde, também, repercute que jornais de outras praças pautam a recuperação. As visitas de autoridades que reconhecem, publicamente, a importância da recuperação é sempre mais um pretexto para novas matérias. Neste ano, o então candidato à presidência da República Fernando Henrique Cardoso foi recebido e levado ao Centro Histórico, por ACM e Luis Eduardo Magalhães; e o presidente de Portugal, Mário Soares, voltou ao Centro Histórico, para mais uma inauguração. As instalações de agências bancárias, albergues, casas de representação de outros países e de outros empreendimentos são reportadas de forma recorrente. Ao todo, foram 11 matérias sobre instalações diversas, algumas sobre o mesmo evento, matérias prévias e coberturas da inauguração. Neste ano, aumenta o turismo no Centro Histórico, como informou a matéria "Cresce o fluxo turístico com boas previsões para o futuro" (A TARDE, 01/12/1994:12), com duas fontes - um diretor de marketing da Bahiatursa e um gerente de hotel de luxo.

Em relação ao ano anterior, a quantidade de unidades jornalísticas diminuiu significativamente, de 166 para 100, uma queda de 39,7\%. Mesmo assim, foi o ano em que as matérias sobre o Centro Histórico de Salvador foram pouco mais da metade do montante daquelas sobre o patrimônio histórico e cultural em geral. Este era o terceiro ano desde que a recuperação tinha sido iniciada. Era o segundo de inaugurações. $E$, também, o ano em que Antonio Carlos Magalhães deixaria o governo para assumir uma vaga no Senado.

Em 1995, foram publicadas 212 matérias sobre o patrimônio histórico e cultural. Aproximadamente, apenas um terço delas tratava do Programa de Recuperação e questões associadas ao Centro Histórico de Salvador. No ano anterior, mais da metade das matérias relativas a patrimônio, o equivalente a $53 \%$, era sobre a recuperação. Portanto, em 1995, apesar de ter havido uma quantidade maior de matérias sobre patrimônio em geral, houve redução das que focaram especificamente na recuperação e no Centro Histórico. O comércio no Pelourinho passa a motivar matérias que informam a diminuição da frequência de visitantes, preços mais altos praticados na área, e dependência dos comerciantes pela visitação de turistas. $E$ a Unesco avalia pesquisa que indica que $22 \%$ dos que frequentavam o Pelourinho moravam nele.

\section{6.- CONSIDERAÇÕES FINAIS}

Não obstante o infindável agendamento promovido pelos meios de comunicação, o qual é perceptivelmente transferido para a agenda dos governos, o Centro Histórico segue enfrentando dificuldades de gestão, as quais comprometem a sua conservação como patrimônio histórico e artístico, e a sua leitura como local que, para manter-se, precisa ser frequentado como qualquer outro, especialmente nas cidades cujos centros se deparam com o esvaziamento, em decorrência da valorização de novos espaços, muitos dos quais privados que acabam por substituir os de tradição.

Não só os moradores remanescentes, mas, também, os comerciantes que se instalaram em suas redondezas, dependem de políticas públicas efetivas que contribuam com a sua conservação ou para que, pelo menos, evitem a intensificação da degradação, há muito em curso. Desde o início do Programa de Recuperação do Centro Histórico de Salvador, o assunto é continuamente agendado especialmente pela mídia impressa que circula na capital baiana, como se pode facilmente constatar verificando o conjunto de matérias publicadas continuamente, por diversos veículos. No presente momento, ainda com a VII Etapa de Recuperação em curso, os atributos mais frequentes das matérias veiculadas voltam a ser os desabamentos e incêndios que têm 
ocorrido nos casarões que integram a poligonal definida pelo Instituto do Patrimônio Histórico e Artístico Nacional (Iphan).

Ao contrário da frequência esparsa que se verificava antes da cobertura dessa experiência, as pautas sobre o patrimônio se multiplicaram durantes os primeiros anos da recuperação e permanecem eventualmente sendo publicadas, agora com criticas recorrentes dirigidas à falta de efetividade das medidas tomadas em prol do agonizante Centro Histórico. Essa postura substitui a cobertura direcionada apenas a situações contingenciais.

Mais importante ainda é que a questão dos moradores do Centro Histórico, que no início da recuperação foi relegada, entrou definitivamente na pauta. É reiterada abertamente nos discursos que se fazem referentes ao Centro Histórico de Salvador a questão da presença de antigos ocupantes. Ou sobre a presença de novos moradores. Contraditoriamente, outros espaços da cidade correm o risco da gentrificação e o problema é rasamente mencionado, como nas áreas do Largo 2 de Julho, no Santo Antônio Além do Carmo e até na Barra, que desde meados de 2013 vive a iminência de uma grande reforma proposta pelo poder municipal cujo governante, ACM Neto, é neto do governador da Bahia à época da chamada recuperação do Centro Histórico de Salvador. Recentemente, no Largo de São Francisco, em frente à Igreja e Convento de São Francisco, que também se encontra em estado de conservação precário, foi inaugurado um museu em homenagem ao exgovernador que lançou o Programa de Recuperação do Centro Histórico.

\section{7.- REFERÊNCIAS BIBLIOGRÁFICAS:}

DEARING, J. W. e ROGERS, E. M.(1992): Communication Concepts 6: Agenda-setting. Thousand Oaks, Ca: Sage.

ESPINHEIRA, C. G. (1971): A comunidade do Maciel. Salvador: Secretaria de Educação e Cultura/Fundação do Patrimônio Artístico e Cultural da Bahia.

(1984): Divergência e prostituição: uma análise sociológica da Comunidade Prostitucional do Maciel. Série Cultura Baiana1. Rio de Janeiro: Tempo Brasileiro; Salvador: Fundação Cultural do Estado da Bahia.

ESTEVES, J. P (2003): Espaço Público e Democracia. Lisboa: Edições Colibri.

(2003): A Ética da Comunicação e os Media Modernos. Legitimidade e Poder nas cidades complexas . $2^{\mathrm{a}}$ Ed.. Lisboa: Fundação Calouste Gulbenkian.

FERNANDES, Ana. Centro Antigo de Salvador: centralidades em disputa e desafios à ação. In: Infocultura Centro Antigo de Salvador: uma região em debate. V. 1, n. 2 (out. 2008). Salvador: Secretaria de Cultura do Estado, Fundação Pedro Calmon Centro de Memória e Arquivo Público da Bahia.

(2006): "Projeto Pelourinho: operação deportação X ampliação dos direitos". Texto contido no Curso de Capacitação - Programas de reabilitação de áreas urbanas centrais. Laboratório de Habitação e assentamentos Humanos da FAU-USP e Lincoln Institute of Land Policy.

(2009): "Projeto Pelourinho: Operação deportação X ampliação do direito", Curso de Capacitação Programas de reabilitação de áreas urbanas centrais. http://www.cidades.gov.br/secretariasnacionais/programas.urbanos/biblioteca/ reabilitacao -de-areas- urbanas-centrais/

FIGUEIREDO FILHO. G. R. de (1984): A influência do ecletismo na Arquitetura Baiana. Revista do Patrimônio Histórico e Artístico Nacional. Rio de Janeiro, n 19.

FORTUNA, C. (1997): Destradicionalização e imagem da cidade. O caso de Évora . In: Cidade, Cultura e Globalização. Org.: Carlos Fortuna. Oeiras: Celta Editora.

GOMES, M. A. F e FERNANDES, A. (1995): Pelourinho: Turismo, Identidade e Consumo Cultural. In: GOMES, Marco Aurélio A. de Filgueiras (Org). Pelo Pelô: História, Cultura e Cidade. Salvador: Editora da Universidade Federal da Bahia/ Mestrado em Arquitetura e Urbanismo - Edufba. 
MATTOSO, Kátia M. (1992): Bahia Século XIX. Uma província no Império . Rio de Janeiro: Editora Nova Fronteira.

MCCOMBS, M. (2007): Setting the Agenda. The Massa Media and Public Opinion. Cambridge: Polity.

McQUAIL, D. (1975): Communication, Aspects of modern sociology. Social Processes. New York: Longman Group.

ROLNIK, R. (2004). O que é cidade? São Paulo: Brasiliense.

SODRÉ, M. (2009): A narração do fato, notas para uma teoria do acontecimento. Petrópolis, RJ: Vozes.

TORRES, C. (1961). Bahia, Cidade feitiço. $2^{\mathrm{a}}$ ed. Salvador: Imprensa Oficial da Bahia.

PINHO, W. A (1990): Coletânea de textos históricos (apresentação Consuelo Ponde de Sena). Salvador: Artes Gráficas.

SANTOS, M. (1959): O Centro da Cidade do Salvador. Estudo de Geografia Urbana. Brasil: Publicações da Universidade da Bahia.

WEAVER, D. H. (2007). Thoughts, Frames and Priming, de David H. Weaver, in Journal of Communication 57 (142-147) at http://www.communicationcache.

com/uploads/1/0/8/8/10887248/thoughts_on_agenda_setting_framing_and_priming.pdf

WEINSTEIN, M. (2011): O patrimônio cultural na imprensa da Bahia: entre o Centro Histórico (anos 90) e a Vitória (anos 2000). Tese de doutoramento inédita. Universidade Federal da Bahia.

WOLF, M. (1987): Teorias da Comunicação. Tradução por: Maria Jorge Vilar de Figueiredo. Tradução de Teorie delle Comunicazioni di Massa. Lisboa: Editorial Presença.

\section{Breve semblanza de la autora:}

Mary Weinstein é professora do Curso de Comunicação/Jornalismo da Universidade Federal do Sudoeste da Bahia (Uesb). Graduada em Comunicação, pela Faculdade de Comunicação da Universidade Federal da Bahia (Ufba), é mestre em Artes Cênicas e Doutora em Cultura e Sociedade, pela mesma universidade. Coordena o grupo de estudo Jornalismo, Cidade e Patrimônio Cultural, que pesquisa a relação entre jornalismo e cidades. Trabalhou como repórter na TV Bahia (Rede Globo) e no Jornal A Tarde, como especializada em Cidade e Patrimônio Cultural.

Ámbitos. Revista Internacional de Comunicación, n.26, año 2014, tercer trimestre (otoño). 